\title{
THE ROLE OF DYNAMIC EXPERIMENTATION FOR COMPUTATION ANALYSIS
}

\author{
L. C. Chhabildas and T. G. Trucano \\ Sandia National Laboratories \\ Experimental Impact Physics \\ Albuquerque, New Mexico 87185-0821
}

\section{INTRODUCTION}

Impact techniques have been used for over four decades to study the dynamic states of matter [1] in temperature and pressure regimes inaccessible by other methods. These techniques have been employed in a wide variety of scientific, military, and commercial applications. Impact studies entail a wide range of topics, such as the constitutive equations of state for materials [2], the study of shock Hugoniots [3], strength of materials [4], fracture and fragmentation [5,6], kinetics of phase transition [7], shock-induced melting and vaporization [8,9], impact cratering [10], and penetration mechanics [11]. A principal objective of determining thermophysical material properties under impact loading is to promote an understanding of physical processes associated with the dynamic material behavior. This can lead to the development and validation of "physically-based" material models that are needed for impact physics hydrodynamic codes [12] for many programmatic applications. With the advancement of high-speed computing capabilities, computational codes are being used much more extensively to predict or optimize the impact response of a system such as an armor configuration. This makes it even more crucial that the material models be sufficiently representative such that the computational analysis and prediction of impact-related events can be performed with confidence. This will, however, require an intimate interaction between dynamic experimentation and computational analysis.

In this paper a brief description of dynamic techniques commonly available for determining material property studies will be presented. For many impact applications the material generally experiences a complex loading path. In most cases, the initial loading conditions can be represented by the shock commonly referred to as the Hugoniot state. Subsequent loading or release structure, i.e., off-Hugoniot states would however be dependent on the physical processes dominating the material behavior. The credibility of the material model is tested by the accuracy of predictions of off-Hugoniot states. Experimental techniques commonly used to determine off-Hugoniot states will be discussed in this survey.

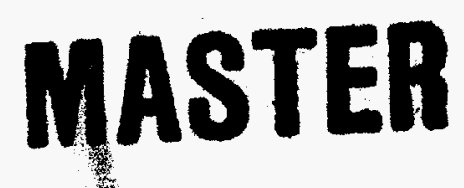

This work was supported by the United States Department of Energy under Contract DE-ACO 


\section{DISCLAIMER}

This report was prepared as. an account of work sponsored by an agency of the United States Government. Neither the United States Government nor any agency thereof, nor any of their employees, makes any warranty, express or implied, or assumes any legal liability or responsibility for the accuracy, completeness, or usefulness of any information, apparatus, product, or process disclosed, or represents that its use would not infringe privately owned rights. Reference herein to any specific commercial product, process, or service by trade name, trademark, manufacturer, or otherwise does not necessarily constitute or imply its endorsement, recommendation, or favoring by the United States Government or any agency thereof. The views and opinions of authors expressed herein do not necessarily state or reflect those of the United States Government or any agency thereof. 


\section{DISCLAIMER}

Portions of this document may be illegible in electronic image products. Images are produced from the best available original document. 


\section{LOADING AND DIAGNOSTIC TECHNIQUES}

Over the last four decades, a variety of high-velocity guns have been developed for material property studies [13]. Gas-driven (helium) guns have a maximum velocity of about $1.4 \mathrm{~km} / \mathrm{s}$ and can produce impact pressures of about $300 \mathrm{kbar}$ in high density materials. Propellant-driven guns can launch projectiles to velocities of about $2.5 \mathrm{~km} / \mathrm{s}$. Impact pressures to about $1 \mathrm{Mbar}$ can be produced in high-impedance materials such as tungsten [14]. Twostage light-gas (hydrogen) guns provide velocities to $8 \mathrm{~km} / \mathrm{s}$ [15]. These launchers allow impact pressures of several Mbar in the laboratory. Gun methods provide more control and precision for producing and probing the material properties in the shocked state. Other recent advances include a modified two-stage gun, which extends projectile velocities to $16 \mathrm{~km} / \mathrm{s}$ for millimeter thickness plates [16]. Impact pressures of $20 \mathrm{Mbar}$ are now feasible in the laboratory. This technique uses the two-stage light gas gun to launch a third-stage projectile with shockless loading methods. Detailed discussions summarizing the capabilities of the different guns developed for dynamic material property studies are given elsewhere $[13,15,16]$.

A unique feature of smooth-bore launchers is that a variety of loading conditions can be achieved and precisely controlled. The basic experiment consists of a simple impact, which produces a single step loading that is maintained for a long time duration compared to shock wave transit in the sample. This method is useful for generating very accurate EOS (shock Hugoniot) data on materials [3]. Another variation is the impact of a multi-layered flyer-plate assembly, which can introduce a variety of shock-structures into the material. A thin flyerplate backed by a low impedance material will introduce a short-duration pressure pulse consisting of a shock followed by an adiabatic release wave. If the back surface of the specimen is a free surface, this technique can be used to determine the dynamic tensile strength (spall strength) of the material $[5,6]$. A series of layered impactors which has a variable shock impedance throughout its thickness $[17,18]$ will generate a quasi-isentropic pressure loading pulse into the material. Since the energy dissipation in the material under quasi-isentropic loading is much less than under shock loading to the same stress, this method will result in lower temperature states of the material at comparable shock loading pressures. Since shockinduced melting can be circumvented with this approach, solid state properties can be studied to very high pressures.

The above methods discussed employ the impact of a standard projectile onto a specimen to determine the specimen dynamic characteristics. There are techniques available which when used can also determine the release adiabats of specimens such as the direct impact of a specimen onto a time-resolved gauge [19], or on a thin witness plate [20].

Experimental determination of material properties requires the use of time-resolved diagnostics for measuring the structure of shock waves. Use of time-resolved gauges on the specimen provides determination of the stress-strain unloading curve from the shocked state. Several techniques have been developed which are discussed in more detail elsewhere $[21,22]$ so that only a brief survey is given here. A variety of pin and optical diagnostics have been developed for measuring shock velocity, which is a basic kinematic property of EOS measurements. Piezoelectric, piezoresistive, electromagnetic and interferometric methods have been used for wave structure measurements. These methods have been used to determine high-pressure material strength, spallation strength, phase transition kinetics and unloading adiabats for materials. 


\section{APPLICATIONS}

Several examples of the capabilities of shock compression methods to determine material properties are provided in the review articles elsewhere [1-8]. A summary of recent examples is presented here.

\subsection{Equation of State}

Gun launchers have been used to a high degree of precision to determine the equation of state or shock Hugoniots for materials up to $5 \mathrm{Mbar}$ on two-stage light-gas guns [22]. The stress range can now be extended to pressures approaching $20 \mathrm{Mbar}$ in high-impedance materials with impact capabilities up to $16 \mathrm{~km} / \mathrm{s}$ [16]. The data is generally represented as a linear relationship between the shock-velocity and the corresponding particle-velocity behind the shock. Any anomaly in the linear shock-velocity vs particle-velocity relationship is attributed to elastic-plastic effects, or to polymorphic phase-transformations accompanied by large volume changes. Time-resolved techniques, combined with sound-speed measurements in the shocked state are generally more accurate and less ambiguous in determining phase transformations in materials which are accompanied by small volume changes such as those reported in calcite [23] or in iron [24] at very high pressures prior to melt. While the phenomenology associated with melt can be accessed at impact velocities achieved on twostage light-gas guns, only the partial-vaporization process can be investigated through the use of low-melting surrogate materials such as zinc, cadmium or lead [8]. The newly developed hypervelocity launch capabilities [16] can be used to investigate full vaporization processes in low-melting and boiling point materials [9].

\subsection{Dynamic Fracture}

Shock wave techniques are also useful in determining the fracture strength of materials. For a variety of engineering applications such as armor design, explosive welding, and recovery fixtures for material synthesis, the final product must survive the high strain-rate loading process. From the standpoint of scientific studies it allows a means of determining nucleation and growth process $[5,6]$ for defect generation and propagation. A basic understanding of these scientific processes is a necessary requirement for developing fracture-resistant materials which approach their theoretical strengths. The mechanism for fracture in a material includes the nucleation of defects (voids or cracks), the growth, propagation, and eventually the coalescence of these defects to form a rupture surface within the material. It is therefore meaningful to discuss the entire fragmentation process in terms of the energy expended in creating the fracture process [5]. The energy consumed in the fracture process can be further related to material properties such as the dynamic yield strength or the fracture toughness by estimating the work done by void growth or in creating a fracture surface [5]. These concepts are crucial for developing material models for use in computational analysis using impact physics codes to predict the fracture and fragmentation behavior of materials. Considerations of the physical processes associated with fracture and fragmentation were essential in recognizing fracture toughness or normalized spall strength as a measure of a materials ability to resist fragmentation, and led to the ability to launch intact plates to hypervelocities $[4,16]$.

\subsection{Dynamic Strength}

It is well known from quasi-static experiments that the yield strength or the ultimate ten- 
sile strength of materials depends on stress, temperature, and the loading rate at which the material is cycled. With the development of dynamic time-dependent loading techniques referred to as quasi-isentropic loading techniques $[17,18]$ one can now determine the temperature, pressure, and loading rate effects on dynamic yield strength, and spall strength of materials to high stresses $[4,26]$. Under shock loading to stresses of interest, the strain rates induced in the shock front are controlled primarily by the material viscosity, whereas under plane quasi-isentropic loading conditions to the same stress, the loading rates can be varied. Under shock loading conditions, the internal energy change of the material is that of the area under the Rayleigh line in the pressure-volume plane, whereas under plane quasi-isentropic compression the internal energy change of the material is given by the area under the isentropic compression curve. For large compressions, the internal energy change of a material under quasi-isentropic compression will be substantially less than that for shock loading to the same stress, resulting in energy (temperature) states that are significantly lower than those obtained on the shock Hugoniot. A comparison of shock loading and quasi-isentropic loading experiments to the same stress will, therefore, allow a determination of pressure, temperature, and rate-dependent properties of materials.

A determination of the dynamic yield strength of tungsten under shock and quasi isentropic loading $[4,26]$ up to $250 . \mathrm{GPa}$, suggests an increase in yield strength with increasing final stress. However, the dynamic yield strength of tungsten under the slower rates of quasi-isentropic loading is a factor of 3 larger than values obtained for shock loading at stresses approaching $250 \mathrm{GPa}$. The temperature of tungsten shocked to $250 \mathrm{GPa}$ is calculated to be $5000 \mathrm{~K}$, whereas under quasi-isentropic compression to $250 \mathrm{GPa}$ it is less than $1000 \mathrm{~K}$.

Determination of the spall strength of tantalum precompressed to $19 \mathrm{GPa}$ and $60 \mathrm{GPa}$ under shock and quasi-isentropic loading, respectively, does indeed indicate an increase in spall strength under quasi-isentropic loading. A spall strength measurement of 8.1 GPa under quasi-isentropic compression is an increase of $27 \%$ when compared to a value of $\sim 6.2 \mathrm{GPa}$ after shock compression to $19 \mathrm{GPa}$. This increase may be a result of slightly lower temperatures and perhaps a lower concentration of defects induced as a consequence of quasi-isentropic loading.

\subsection{Shock Induced Melting}

With increasing shock amplitude, sufficient internal energy is deposited in the shocked material to induce melting. However, the volume change in the shocked material associated with melting is extremely small. Therefore, melting cannot be easily observed either in the shock velocity-particle velocity plane, or, on the shock Hugoniot. As the shocked material approaches the melt boundary, both the shear stress and the shear modulus of the material becomes zero. This causes the sound speed behind the shocked front to transform generally from elastic wave speeds to bulk wave speeds. This technique has been used to detect melting under shock compression in aluminum [27, 28] tantalum [29], iron [25] and quartz [30, 31]. Shock induced melting studies contribute towards validation of the equation of state of materials, with particular emphasis on various melting laws (such as Lindemann's melting law).

\subsection{Shock-Induced Vaporization}

Prediction of the interaction between expanded vapor debris and target materials for applications such as meteorite impact on space vehicles, ballistic penetration of armors, debris shield design, etc., demands an accurate treatment of the melting and vaporization process 
and the kinetics of liquid-vapor propagation. Experimental efforts to understand high-pressure vaporization have been hindered by unavailability of experimental launchers that are capable of speeds needed to induce vaporized states. This problem has been alleviated to some extent by studying materials which have relatively low melting and boiling points $[8,32]$. Recently the hypervelocity launcher [16] has been used at impact speeds of 8 to $10 \mathrm{~km} / \mathrm{s}$ to investigate zinc to full vaporization [9]. Significant discrepancies between experiment and calculation exist based on current equation of state assumptions. This study highlights the danger of extrapolating low pressure data to very high pressures even though the low pressure phenomenology is well represented by the material model. For materials of greater programmatic interest such as aluminum, an alternative is to shock porous samples $[31,32]$. Experiments using porous samples, in combination with higher initial temperatures shocked to very high-pressures at impact speeds approaching $16 \mathrm{~km} / \mathrm{s}$ would substantially increase the concentration of vapor in engineering materials [9].

\section{OTHER USES OF HIGH VELOCITY LAUNCHERS}

In addition to material property studies, high-velocity launchers are fundamental to a variety of other applications. These include guns that have been designed specifically to study materials subjected to ballistic loading, such as projectile or meteorite impact. Dynamic phenomena of importance in these studies concerns the failure response of target and projectile materials and the effects of debris in the form of solid, liquid or finely dispersed fragments or vapor produced during failure of these components. Analysis of this debris and the interaction of the debris with other components is fundamentally important in several applications, including the design of better armors for weapon systems and the design of debris shields for spacecraft.

\section{REFERENCES}

[1] L. W. Davison and R. A. Graham, Shock Compression of Solids Phys. Rep., 55, Vol. 55, (1979), pp. 257--379.

\{2\} J. R. Asay and G. I. Kerley, The Response of Materials to Dynamic Loading, Int. J. Impact Engg., Vol.5, (1987), pp. 69-99.

[3] S. P. Marsh, LASL Shock Hugoniot Data, University of California, Berkeley, 1980.

[4] L. C. Chhabildas, L. M. Barker, J. R. Asay, and T. G. Trucano, Relationship of Fragment Size to Normalized Spall Strength for Materials, Int. J. Impact Engg., Vol. 10, (1990b) pp. 107-124.

[5] D. E. Grady, The Spall Strength of Condensed Matter, J. Mech. Phys. Solids, Vol. 36, (1988) pp. 353-369.

[6] D. R. Curran, L. Seaman, and D. A. Shockey, Dynamic Failure of Solids, Physics Reports, Vol. 147, (1987), pp. 253-388.

[7] G. E. Duvall and R. A. Graham Rev. Modern Phys., Vol. 49, (1977),pp. 523--579.

[8] J. R. Asay, T. G. Trucano, and R. S. Hawke, The use of Hypervelocity Launchers to Explore Previously Inaccessible State of Matter, Int. J. Impact Engg., Vol. 10, (1990) pp. 51-66.

[9] R. M. Brannon and L. C. Chhabildas, Experimental and Numerical Investigation of ShockInduced Full Vaporization of Zinc, Int. J. Impact Engg., (1995) (in print).

[10] H. J. Melosh, Impact Cratering, A Geological Process, Oxford University Press, 1989.

[11] M. E. Backman and W. Goldsmith, The Mechanics of Penetration of Projectiles into Targets, Int'l. J. Engr. Sci., Vol. 16, pp. 1-99.

[12] J. M. McGlaun, S. L. Thompson, and M. G. Elrick, CTH: A Three-Dimensional ShockWave Physics Code, Int. J. Impact Engg., Vol. 10, (1990), pp. 351-360. 
[13] L. C. Chhabildas and R. A. Graham, Developments in Measurement Techniques for Shock Loaded Solids, in Techniques and Theory of Stress Measurements for Shock Applications-AMD Vol. 83, Amer. Soc. Mech. Engr., N.Y. (1989), pp. 1- 16.

[14] J. R. Asay, L. C. Chhabildas, L. M. Barker, Projectile and Impactor Designs for Plate-Impact Experiments, Sandia National Laboratories Report, SAND85-2009 (unpublished).

[15] A. C. Charters, Development of the High-Velocity Gas-Dynamics Gun, Int'1 J. of Impact Engr., Vol. 5, (1986), pp. 181-203.

[16] L. C. Chhabildas, L. N. Kmetyk, W. D. Reinhart, C. A. Hall, Enhanced Hyper-velocity Launcher Capabilities to 16 km/s, Int'1 J. of Impact Engr., Vol. xx, (1995), pp. 181-203.

[17]. L. M. Barker, High-Pressure Quasi-Isentropic Experiments. J. R. Asay, R. A. Graham, and G. K. Straub (eds) Shock Waves In Condensed Matter--1983, Elsevier Science Publ., B.V., (1984), 217-224.

[18]. L. C. Chhabildas, and L. M. Barker, Dynamic Quasi-Isentropic Compression of Tungsten, Shock Waves in Condensed Matter - 1987, S. C. Schmidt, N. C. Holmes (editors), Elsevier Science Publishers B.V., (1988) pp. 111.

[19]. M. D. Furnish and D. E. Grady, Dynamic Compression and Release Experiments on Indiana Limestone, Shock Waves in Condensed Matter - 1989, S. C. Schmidt, J. N. Jonson, and L. W. Davison (eds), Elsevier Science Publishers B.V. , (1990) pp. 625-628.

[20] L. C. Chhabildas and D. E. Grady, Dynamic Material Response of Quartz at High Strain Rates, Mat. Res. Soc. Symp. Proc., Vol 22, C. Homan, et al., (eds), Elsevier Science Publishers, (1984), pp. 147-150.

[21] L. C. Chhabildas, Survey of Diagnostic Tools Used in Hypervelocity Impact Studies, Int'1 J. of Impact Engr., Vol. 5, (1986), pp. 205-220.

[22] R. A. Graham and J. R. Asay, Measurements of Wave Profiles in Shock Loaded Solids, High Temperatures--High Pressures, Vol 10, (1978), pp. 355--390.

[23] D. E. Grady, High-Pressure Release Wave Measurement and Phase Transformation in Calcite, Y. M. Gupta (ed), Shock Waves in Condensed Matter, Plenum (1986), pp. 601-604.

[24] J. M. Brown and R. G. McQueen, Geophys. Res. Letters 7, (1980), 533-536.

[25] J. M. Brown and J. W. Shaner, Shock Waves in Condensed Matter - 1983, J. R. Asay et al., (eds), Elsevier Science Publishers B.V., (1984) pp. 91-94.

[26] L. C. Chhabildas and J. R. Asay, Quasi-Isentropic Compression Techniques for Material Property Studies, EXPLOMET, Shock Waves and High-Strain-Rate Phenomena in Metals, edited by M. A. Meyers, L. E. Murr, and K. P. Staudhammer (1991).

[27] R. G. McQueen, J. N. Fritz, and C. E. Morris, The Velocity of Sound Behind Strong Shock Waves in 2024 Al. J. R. Asay, R. A. Graham, and G. K. Straub (eds), Shock Waves in Condensed Matter--1983, Elsevier Science Publ., B.V., (1984) pp. 95--98.

[28] J. R. Asay, L. C. Chhabildas, T. G. Trucano, G. I. Kerley, High-Pressure Strength of Shocked Aluminum, Y. M. Gupta (ed), Shock Waves in Condensed Matter, Plenum Publishing, (1986), pp. 145-149.

[29] G. A. Lyzenga, T. J. Ahrens, and A. C. Mitchell, J. Geophys. Res., 88, (1983), 2431-2444. [30] L. C. Chhabildas, Shock Loading and Release Behavior of X-cut Quartz, Y. M. Gupta (ed), Shock Waves in Condensed Matter, Plenum Publishing, (1986), pp. 601-604.

[31] G. I. Kerley and J. L. Wise, Shock-Induced Vaporization of Porous Aluminum, Shock Waves in Condensed Matter - 1987, S. C. Schmid and N. C. Holmes (eds), Elsevier Science Publishers B.V. , (1990) pp. 625-628.

[32] J. L. Wise, G. I. Kerley, T. G. Trucano, Shock-Vaporization Studies on zinc and porous carbon, Shock Waves in Condensed Matter - 1991, S. C. Schmidt, R. D. Dick, J. W. Forbes, D. G. Tasker, (eds), Elsevier Science Publishers B.V. , (1992) pp. 1025-1028. 